\section{Development of Anti-CCP-positive Rheumatoid Arthritis Following Pegylated Interferon- $\alpha 2 a$ Treatment for Chronic Hepatitis C Infection}

To the Editor:

Interferon- $\alpha$ (IFN- $\alpha)$ is a group of cytokines with antiviral and antiproliferative effects, used for the treatment of chronic hepatitis $\mathrm{C}$ infection and various malignancies ${ }^{1}$. Immunomodulatory effects of IFN may lead to the induction or exacerbation of autoimmune diseases such as psoriasis, systemic lupus erythematosus, and rarely, rheumatoid arthritis (RA) ${ }^{1}$. Covalent attachment of a polyethylene glycol (PEG) moiety (pegylation) to IFN- $\alpha$ results in a significantly higher sustained virological response rate in patients with chronic hepatitis C compared to conventional IFN- $\alpha^{2}$. Pegylation also reduces the immunogenicity of IFN- $\alpha^{2}$. We describe the first case of a patient who developed anticyclic citrullinated peptide antibody (anti-CCP)-positive RA following treatment of chronic hepatitis $\mathrm{C}$ infection with pegylated IFN- $\alpha 2 \mathrm{a}$.

A 54-year-old Chinese man with chronic hepatitis $\mathrm{C}$ (genotype 2a) infection was placed on a 24-week course of PEG-IFN- $\alpha 2$ a $180 \mu$ g weekly and ribavirin $400 \mathrm{mg}$ BID. His hepatitis C virus (HCV) RNA became undetectable at Week 12 and remained undetectable throughout his treatment. With no history of arthritis, he developed a diffuse pain syndrome 18 weeks into antiviral treatment. Initially this was attributed to myalgias or possible myositis, but creatine phosphokinase (CPK) and aldolase levels were normal. Treatment with ibuprofen $200 \mathrm{mg}$ every $6 \mathrm{~h}$, celecoxib 200 $\mathrm{g} /$ day, and tramadol $100 \mathrm{mg}$ every $6 \mathrm{~h}$ provided only minimal relief. Upon completion of a 24-week course of antiviral therapy he developed a sustained virological response as evidenced by persistent undetectable $\mathrm{HCV}$ RNA and normal aminotransferase activities. However, by the end of his 24 weeks of antiviral therapy, he developed bilateral pain in his shoulders, elbows, hands, knees, and feet. The musculoskeletal examination was notable for active synovitis of the proximal phalangeal joints, metacarpophalangeal joints, wrists, elbows, shoulders, knees, ankles, and feet. Distal interphalangeal joints were spared. Handgrip was $50 \%$ of normal. He had no musculoskeletal symptoms prior to antiviral therapy. Review of systems was otherwise unremarkable. Laboratory results revealed anti-CCP $41.27 \mathrm{IU} / \mathrm{ml}$ (negative $<5 \mathrm{IU} / \mathrm{ml}$ ), erythrocyte sedimentation rate $163 \mathrm{~mm} / \mathrm{h}$, C-reactive protein $>192 \mathrm{mg} / \mathrm{l}$ (normal < $6 \mathrm{mg} / \mathrm{l}$ ), CPK $17 \mathrm{U} / 1$ (normal 24-170 U/1), negative antinuclear antibodies, undetectable cryoglobulins, negative rheumatoid factor $(\mathrm{RF}$; normal $<8 \mathrm{IU} / \mathrm{ml})$, hemoglobin $11.3 \mathrm{~g} / \mathrm{dl}$, and thyroid-stimulating hormone $3.18 \mathrm{IU} / \mathrm{ml}$. Radiographs showed juxtaarticular osteopenia and early erosions of wrist joints. A positive tuberculin skin test precluded the initiation of an anti-tumor necrosis factor- $\alpha$ agent. Instead he was treated with hydroxychloroquine $400 \mathrm{mg}$ and sulfasalazine $2 \mathrm{~g} / \mathrm{day}$, which resulted in dramatic improvement of symptoms.

IFN- $\alpha$ has rarely been reported to induce or exacerbate RA in patients with chronic hepatitis $\mathrm{C}$ infection ${ }^{1}$. Okanoue, et al reported that out of 677 patients treated with high-dose nonpegylated IFN for chronic hepatitis $\mathrm{C}$ infection, 2 patients developed $\mathrm{RA}^{3}$. Most case reports of patients developing RA after treatment with nonpegylated IFN for hepatitis $\mathrm{C}$ show persistent arthritis unresponsive to nonsteroidal antiinflammatory drugs despite discontinuation of IFN therapy $1,4,5,6$.

Induction of RA following IFN- $\alpha$ treatment should be differentiated from HCV-related inflammatory arthritis, which has been described as falling loosely into 2 subsets $^{7}$. One subset, associated with mixed cryoglobulinemia, is usually monoarticular or oligoarticular, and follows an intermittent course. The other is a symmetrical RA-like polyarthritis in which erosions and rheumatoid nodules are usually absent, although RF is present. Patients with HCV-related arthritis can be distinguished from those with RA by the absence of anti-CCP titers ${ }^{7}$. HCV-related arthritis often improves after treatment with IFN- $\alpha$, even without complete virological response ${ }^{7}$. In the absence of hepatitis $\mathrm{C}$ viremia and detectable cryoglobulinemia, it is unlikely that our patient's arthritis was HCV-related.
Introduction of pegylated formulations of IFN has been hypothesized to minimize the risk for autoimmune induction by reducing immunogenicity $^{2}$. Only 2 cases of RA associated with PEG-IFN treatment for hepatitis $\mathrm{C}$ have been reported in the English literature ${ }^{8,9}$. Although anti-CCP can be used to distinguish HCV-related arthritis from RA, the presence of anti-CCP has not been reported in IFN-associated RA. Anti-CCP has been found to be predictive of more severe joint destruction in $\mathrm{RA}^{10}$. Unlike the 2 reported patients with PEG-IFN-associated RA, our patient demonstrated severe erosive disease.

The possibility of pegylated IFN inducing or exacerbating RA in previously predisposed individuals should be considered in patients with hepatitis $\mathrm{C}$ who develop arthritis. Screening for RF and anti-CCP may be considered before treating with IFN. Detection of anti-CCP, the presence of nodules, and erosive disease help distinguish RA from HCV-related arthritis, but these characteristics are not always found in patients who develop RA with IFN treatment. The prognosis of patients with PEG-IFN-associated RA remains unclear because of the small number of cases reported. If the symptoms of RA do not resolve after discontinuing PEG-IFN, these patients may require treatment with disease-modifying antirheumatic drugs.

DARICE YANG, MD; DANIEL ARKFELD, MD, Division of Rheumatology, USC Keck School of Medicine, Rheumatology, 2011 Zonal Avene, HMR 711, Los Angeles, California 90033, USA; TSE-LING FONG, MD, Division of Gastrointestinal and Liver Diseases, Keck School of Medicine, University of Southern California (USC). Address correspondence to Dr. Arkfeld; E-mail: arkfeld@usc.edu

\section{REFERENCES}

1. Nesher G, Ruchiemer R. Alpha-interferon-induced arthritis: clinical presentation, treatment, and prevention. Semin Arthritis Rheum 1998;27:360-5.

2. Harris JM, Chess RB. Effect of pegylation on pharmaceuticals. Nature 2003;2:214-21.

3. Okanoue T, Sakamoto S, Itoh Y, Minami M, Yasui K, Sakamoto M, et al. Side effects of high-dose interferon therapy for chronic hepatitis C. J Hepatol 1996;25:283-91.

4. Chung A, Older SA. Interferon-alpha associated arthritis. J Rheumatol 1997;24:1844-5.

5. La Civita L, Fadda P, Gaudiano C, Bentivenga C, Olivieri I. Can hepatitis $\mathrm{C}$ virus infection and interferon-alpha undo the HLA-DRB $1 * 0402 / D Q B 1 * 0302$ protection against rheumatoid arthritis? Rheumatology 2003;42:383-4.

6. Nadir F, Fagiuoli S, Wright HI, Nadir A, Hopp E, Gavaler J, et al. Rheumatoid arthritis: a complication of interferon therapy. J Okla State Med Assoc 1994;87:228-30.

7. Zuckerman E, Keren D, Rozenbaum M, Toubi E, Slobodin G, Tamir A, et al. Hepatitis C virus-related arthritis: Characteristics and response to therapy with interferon alpha. Clin Exp Rheumatol 2000;18:579-84.

8. Ionescu C, Micu L, Constantinescu I, Hortopan M, Ursaciuc C, Voiculescu M. Prolonged treatment with interferon alpha and peginterferon induces rheumatoid arthritis syndrome and erythema nodosum. J Gastrointestin Liver Dis 2008;17:211-2.

9. Sood A, Midha V, Sood N. Rheumatoid arthritis probably induced by pegylated interferon in a patient with chronic hepatitis $\mathrm{C}$. Indian J Gastroenterol 2004;23:28-9.

10. Vallbracht I, Rieber J, Oppermann M, Forger F, Siebert U, Helmke K. Diagnostic and clinical value of anti-cyclic citrullinated peptide antibodies compared with rheumatoid factor isotypes in rheumatoid arthritis. Ann Rheum Dis 2004;63:1079-84.

J Rheumatol 2010;37:8; doi:10.3899/jrheum.100092

Personal non-commercial use only. The Journal of Rheumatology Copyright (C) 2010. All rights reserved. 